\title{
KELAYAKAN USAHA PENYULINGAN MINYAK ATSIRI BERDASARKAN ASPEK FINANSIAL DAN TEKNOLOGI
}

\section{FEASIBILITY OF ESSENTIAL OIL REFINING BASED ON FINANCIAL ASPECT AND TECHNOLOGY}

\author{
${ }^{1}$ Jemi Cahya Adiwijaya, ${ }^{2}$ Uyun Erma Malika \\ ${ }^{1,2}$ Program Studi Manajemen Agribisnis Jurusan Manajemen Agribisnis Politeknik Negeri Jember \\ Jalan Mastrip Kotak Pos164 Jember \\ jemiadiwijaya356@gmail.com
}

\begin{abstract}
Abstrak
Minyak atsiri adalah minyak yang dihasilkan dari proses penyulingan tanaman yang komponennya secara umum mudah menguap.Peluang pasar minyak atsiri masih sangat terbuka luas mengingat semakin bertambahnya industri pengguna baik di tingkat nasional maupun internasional. Adapun tujuan dari penelitian ini adalah untuk mengetahui kelayakan usaha penyulingan minyak atsiri berdasarkan aspek finansial, dan untuk mengetahui kelayakan usaha penyulingan minyak atsiri berdasarkan aspek teknologi. Penelitian ini dilakukan di usaha penyulingan minyak atsiri UD Barokah Atsiri yang berlokasi di Desa Kemuning Lor Kecamatan Arjasa Kabupaten Jember. Pemilihan lokasi dilakukan secara sengaja (purposive). Hasil penelitian ini menunjukkan bahwa usaha penyulingan minyak atsiri tersebut dinilai layak dari aspek finansial dengan Nilai NPV sebesar Rp 224.535.234, Net B/C 1,89, IRR 36\% dan Pay Back Period(PBP)selama 1 tahun 6 bulan. Teknologi peralatan yang digunakan oleh UD.Barokah Atsiri dalam operasional proses penyulingan juga dapat dinilai layak. Peralatan yang digunakan sudah berbahan modern sehingga tidak mempengaruhi kualitas minyak yang dihasilkan.
\end{abstract}

Kata kunci: minyak atsiri, NPV, IRR, Net B/C, PBP

\begin{abstract}
Essential oils are produced from the refining process plant whose components are generally volatile. The market opportunity of essential oil is still very open, considering the increasing number of user industries at national and internationallevel. The research purposes consisted to determine the feasibility of essential oil refining which based on the financial aspects, and to determine the feasibility of essential oil refining which based on technological aspects. This research was conducted in the essential oil refining business "UD Barokah Atsiri" which located in Kemuning Lor Arjasa District of Jember. The choice of location is done intentionally (purposive). The results of this research indicate that the oil refining business is considered feasible from a financial aspect to the NPV value of Rp 224535 234, Net B / C 1.89, IRR 36\% and Payback Period (PP) for 1 year and 6 months. Technological equipment used by UD.Barokah Essential operational refining process can also be considered feasible. It is made of modern so it does not affect the quality of oil produced.
\end{abstract}

Key words: essential oil, NPV, IRR, Net B/C, PP

\section{PENDAHULUAN}

Minyak atsiri adalah minyak yang dihasilkan dari proses penyulingan tanaman yang komponennya secara umum mudah menguap. Minyak atsiri ini dapat diperoleh dari beberapa tanaman yang menjadi sumber minyak atsiri, dimana sumber minyak atsiri bisa terdapat pada bagian daun, akar, bunga, biji, ataupun kulit. Adapun tanaman penghasil minyak atsiri ini antara lain tanaman akar wangi, cengkeh, pala, kenanga, cendana, serai, nilam dan sebagainya.
Minyak atsiri menjadi salah satu komoditi ekspor yang menghasilkan devisa cukup tinggi, dimana di Indonesia banyak terdapat cukup banyak tanaman penghasil minyak atsiri. Menurut Balai Penelitian Tanaman obat dan Rempah (Balittro) menyatakan bahwa Indonesia saat ini termasuk dalam tujuh negara produsen terbesar minyak atsiri dunia. Peluang pasar minyak atsiri masih sangat terbuka luas mengingat semakin bertambahnya industri pengguna baik di tingkat nasional maupun internasional.

Rendahnya produktivitas dan mutu minyak atsiri antara lain disebabkan rendahnya mutu 
Jemi Cahya Adiwijaya, Uyun Erma Malika, Kelayakan Usaha Penyulingan Minyak Atsiri Berdasarkan Aspek Finansial dan Teknologi

genetik tanaman, teknologi budidaya yang masih sederhana, serta proses pasca panen yang belum tepat. Teknologi pengolahan minyak atsiri (penyulingan) pada dasarnya sudah tersedia, namun teknologi tersebut belum semuanya diadopsi oleh petani, mengingat proses teknologi modern juga memerlukan investasi yang cukup tinggi, karena keterbatasan modal menyebabkan terdapat beberapa pengusaha industri penyulingan minyak atsiri yang belum mampu mengadopsi seluruh teknologi tersebut. Dalam kegiatan penelitian ini akan dilakukan analisis kelayakan usaha agroindustri penyulingan minyak atsiri. Berdasarkan uraian latar belakang yang telah dikemukakan, maka perlu dilakukan penelitian tentang tingkat kelayakan usaha penyulingan minyak atsiri. lain:

Adapun tujuan dari penelitian ini antara

(1) Mengetahui kelayakan usaha penyulingan minyak atsiriberdasarkan aspek finansial.

(2) Mengetahui kelayakan usaha penyulingan minyak atsiri berdasarkan aspek teknologi

\section{METODOLOGI PENELITIAN}

Penelitian ini dilakukan di usaha penyulingan minyak atsiri UD Barokah Atsiri yang berlokasi di Desa Kemuning Lor Kecamatan Arjasa Kabupaten Jember. Pemilihan lokasi dilakukan secara sengaja (purposive) dengan berbagai pertimbangan bahwa UD Barokah Atsiri merupakan salah satu sentra tempat penyulingan minyak atsiri dan satu-satunya usaha penyulingan minyak atsiri yang terdaftar di di Dinas Perindustrian dan Perdagangan (Disperindag) Kabupaten Jember.

Penelitian ini merupakan penelitian deskriptif kuantitatif. Analisis deskriptif dilakukan untuk menggambarkan sistem usaha dan aspek teknologi yang digunakan di usaha penyulingan minyak atsiri di UD Barokah Atsiri. Teknologi tersebut akan dibandingkan dengan teknologi penyulingan minyak atsiri yang diperoleh dari studi literatur, baik literatur dari hasil penelitian terdahulu maupun dari studi teoritis dari bukubuku yang membahas tentang penyulingan minyak atsiri. Analisis secara kuantitatif digunakan untuk mengetahui tingkat kelayakan berdasarkan aspek finansial.

Data yang digunakan dalam penelitian ini terdiri dari data primer dan data sekunder. Data primer merupakan data yang diperoleh melalui pengamatan langsung, wawancara, dan mengikuti seluruh aktivitas yang dilakukan dalam usaha penyulingan minyak atsiri di UD Barokah Atsiri. Data sekunder merupakan data yang diperoleh melalui studi literatur dari berbagai dokumen maupun catatan dari usaha penyulingan minyak atsiri UD Barokah Atsiri, serta berbagai informasi yang diperoleh dari instansi-instansi yang terkait.

Analisis secara kuantitatif digunakan untuk mengetahui tingkat kelayakan berdasarkan aspek finansial. Dalam penghitungan analisis kelayakan terdapat penggunaan sejumlah barang investasi yang memerlukan waktu pengembalian yang cukup panjang maka dalam proses penghitungan ini akan diperhitungkan konsep time value of money, dengan konsep ini penentuan nilai uang sekarang dan yang akan datang harus dilakukan dengan metode discounting factor. Metode kuantitatif yang akan digunakan adalah analisis kelayakan finansial berdasarkan kriteria NPV, Net B/C, PP, dan IRR dengan penjelasan sebagai berikut:

\section{a. $\quad$ Net Present Value (NPV)}

Net Present Value(NPV) suatu proyek adalah selisih PV arus benefit dengan PV arus biaya(Gray dkk, 2007).Rumus perhitungannya sebagai berikut:

$$
N P V=\sum_{i=0}^{n} \frac{B t-C t}{(1+i)^{t}}
$$

Keterangan:

Bt : Penerimaan total pada tahun ke-t (Rp)

$\mathrm{Ct}$ : Biaya total pada tahun ke-t (Rp)

n : Umur proyek (tahun)

$\mathrm{t} \quad$ : Tahun ke $1,2.3, \ldots, \mathrm{n}$

i : Discount rate $(\%)$

Terdapat tiga kriteria penilaian kelayakan dari NPV yaitu, (1) Jika nilai NPV suatu bisnis lebih besar dari nol (NPV > 0), maka proyek layak untuk dilaksanakan; (2) Jika nilai NPV yang dihasilkan suatu bisnis lebih kecil dari nol (NPV < 0), maka proyek tidak layak untuk dilaksanakan; (3) Jika perhitungan cashflow menghasilkan nilai NPV sama dengan nol (NPV $=0)$, maka proyek tidak menguntungkan dan tidak merugikan, tetapi proyek masih layak untuk dilaksanakan.

b. Net Benefit and Cost Ratio(B/C)

Net Benefit and Cost Ratio(Net B/C Rasio) merupakan angkaperbandingan antara present value dari net benefit yang positif dengan presentvaluedarinet benefityang negatif (Gray dkk, 2007).Rumus perhitunganya adalah sebagai berikut:

$$
\text { Net } B / C=\frac{\sum_{i=0}^{n} \frac{B t-C t}{(1+i)^{t}}}{\sum_{i=0}^{n} \frac{B t-C t}{(1+i)^{t}}} \frac{\text { untuk Bt }-C t>0}{\text { untuk Bt }-C t<0}
$$

Keterangan: 


\author{
Bt : Penerimaan total pada tahun ke-t (Rp) \\ $\mathrm{Ct} \quad$ : Biaya total pada tahun ke-t (Rp) \\ n : Umur proyek (tahun) $\mathrm{t}$ : Tahun ke 1, 2. \\ $3, \ldots, \mathrm{n}$ \\ i : Discount rate (\%) Kriteria kelayakan \\ dari Net B/C:
}

Adapun kriteria yang digunakan dalam penghitungan Net B/C adalah sebagai berikut: (a) Net $\mathrm{B} / \mathrm{C}>1$, maka bisnis layak untuk dilaksanakan, artinya setiap pengeluaran akan menghasilkan penerimaan yang lebih besar dari pengeluaran tersebut; (b) Net $\mathrm{B} / \mathrm{C}<1$, maka bisnis tidak layak untuk dilaksanakan, artinya setiap pengeluaran akan menghasilkan penerimaan yang lebih kecil dari pengeluaran tersebut.

c. Internal Rate of Return(IRR)

Metode Internal Rate Return (IRR) merupakan metode penilaian investasi untuk mencari tingkat bunga yang menyamakan nilai sekarang dari aliran kas netto (present valu of proceeds) dan investasi (initial outlays). Pada saat IRR tercapai, maka besarnya NPV sama dengan nol. Oleh karena itu, untung menghitung IRR diperlukan data NPV dari kutub (daerah) positif dan kutub negative kemudian dilakukan interpolasi (pencarian nilai selisih) sehingga diperoleh NPV sama dengan nol (Martono dan Agus Harjito 2008).Rumus perhitunganya adalah sebagai berikut:

$$
I R R=r k+\frac{N P V r k}{P V r k-P V r b} x(r b-r k)
$$

Keterangan:

rk : tingkat bunga yang kecil (rendah)

rb : tingkat bunga yang besar (tinggi)

NPV rk : NPV pada tingkat bunga yang kecil

PV rk : Present Value of Proceeds pada tingkat bunga yang kecil

PV rb : Present Value of Proceeds pada tingkat bunga yang besar

Adapun kriteria kelayakan dari IRR adalah sebagai berikut: (a) IRR > Opportunity Cost of Capitalatau Discount Ratemaka bisnis layak untuk dilaksanakan; (b) IRR <Opportunity Cost of Capitalatau Discount Ratemaka bisnis tidak layak untuk dilaksanakan.

\section{d. Payback Period(PP)}

Payback Periodadalah suatu periode yang diperlukan untuk menutup kembali pengeluaran investasi (initial cash investment) dengan menggunakan aliran kas, dengan kata lain payback period merupakan rasio antara initial cash investment dengan cash inflow yang hasilnya merupakan suatu waktu (Umar, 2003). Rumus didapat dari usaha penyulingan minyak atsiri tiap tahunnya. Sumber penerimaan yang merupakan perhitunganya adalah sebagai berikut:

$$
P P=\frac{I}{A b}
$$

Keterangan:

PP : Waktu yang diperlukan untuk mengembalikan modal (tahun)

I : Jumlah modal investasi (Rp)

$\mathrm{Ab} \quad$ : Manfaat hasil bersih rata-rata per tahun periode (Rp)

\section{HASIL DAN PEMBAHASAN}

UD Barokah Atsiri merupakan salah satu usaha penyulingan minyak atsiri. UD Barokah atsiri didirikan sejak tahun 2004 dengan nama pemilik Bapak Junaidi. UD Barokah atsiri berlokasi di Desa Kemuning Lor Kecamatan Arjasa Kabupaten Jember. UD Barokah atsiri ini terletak pada areal dengan luasan sekitar 300 $\mathrm{m}^{2}$.Adapun komoditas yang disuling di UD Barokah atsiri antara lain tanaman nilam, sereh wangi dan cengkeh. Tanaman atsiri yang disuling diperoleh dengan membeli dari para petani nilam, sereh dan cengkeh. Komponen alat penyulingan yang ada di UD Barokah terdiri dari ketel, pipa pendingin dan jedingan. Kapasitas alat penyulingan minyak atsiri di UD Barokah termasuk kapasitas sedang dengan kemampuan ketel dapat menampung sekitar 1,6 ton nilam basah atau sekitar 3 kwintal nilam kering. Bahan bakar yang digunakan untuk memanaskan ketel penyulingan tersebut adalah kayu bakar.

Bapak Junaidi selaku pemilik UD Barokah atsiri memiliki dua orang pegawai yang bertugas pada proses penyulingan dan dua orang lagi bertugas untuk menjemur dan mengeringkan tanaman yang akan disuling. Kegiatan penyulingan dapat dilakukan sebanyak 2 kali dalam 24 jam. Jika musim panen, penyulingan bisa dilakukan hampir tiap hari selama 6 hari kerja (hari jum'at libur).

Analisis aspek finansial pada usaha penyulingan minyak atsiri pada UD.Barokah Atsiri dilakukan untuk mengetahui kelayakan usaha, sehingga hasil dari output penelitian ini diharapkan dapat menjadi rekomendasi pertimbangan dalam melaksanakan pengembangan investasi skala usaha. Kelayakan finansial yang diperhitungkan dalam penelitian ini dilakukan tanpa pertimbangan risiko. Komponen dari aspek yang dikaji pada analisis aspek finansial adalah sebagai berikut:

(a) Arus Manfaat

Manfaat yang diterima dari usaha penyulingan minyak atsiri pada UD.Barokah Atsiri merupakan hasil penerimaan bagi pemilik. Manfaat adalah segala hasil penerimaan yang manfaat dari kegiatan penyulingan minyak atsiri adalah penerimaan hasil penjualan minyak atsiri 
Jemi Cahya Adiwijaya, Uyun Erma Malika, Kelayakan Usaha Penyulingan Minyak Atsiri Berdasarkan Aspek Finansial dan Teknologi

berbahan baku nilam. Selain dari penerimaan tersebut, pemilik juga memperoleh penerimaan nilai sisa dari barang-barang investasi yang telah habis masa pakai umur ekonomisnnya. Nilai sisa dari barang-barang investasi tersebut diperhitungkan sebagai hasil tambahan dalam komponen penerimaan perhitunga cashflow. Manfaat usaha sudah dapat diperoleh pada tahun pertama pelaksanaan proyek setelah kegiatan investasi yakni pembuatan bangunan dan ketel penyulingan minyak atsiri dikerjakan.

Manfaat yang diterima dari hasil penjualan minyak atsiri berbahan baku nilam pada tahun pertama sejumlah Rp 220.500.000. Pada tahun ke dua penerimaan yang diperoleh UD.Barokah Atsiri menurun jika dibandingkan tahun pertama yaitu sebesar Rp 143.437.500, hal tersebut terjadi karena terjadi penurunan harga minyak nilam per liter dari Rp 1.000.000 turun ke harga $\mathrm{Rp}$ 425.000. Pada tahun ke tiga penerimaan yang diperoleh UD.Barokah Atsiri menurun drastis yaitu sebesar $\mathrm{Rp} 38.250 .000$, hal tersebut dikarenakan terjadi peremajaan tanaman nilam setelah tiga tahun jadi harus menunggu pada bulan ke tujuh untuk melakukan pemanenan. Tahun ke empat penerimaan yang diperoleh yaitu sebesar Rp 194.400.000 kemudian pada tahun ke lima penerimaan yang diperoleh UD.Barokah Atsiri sebesar Rp 158.730.000. Kenaikan penerimaan yang terjadi pada tahun ke empat dan ke lima disebabkan oleh kenaikan harga minyak atsiri berbahan baku nilam berada di harga Rp 450.000 sampai Rp 550.000.

Pada tahun ke enam penurunan penerimaan kembali terjadi sebesar Rp 55.935.000 , hal tersebut terjadi karena peremajaan dari tanaman nilam setiap 3 tahun. Selanjutnya untuk tahun ke tujuh dan ke delapan mengalami penurunan yang sangat drastis yaitu sebesar Rp 43.200.000 dan Rp 19.800.000, hal tersebut terjadi karena banyak dari petani yang mengubah komoditasnya. Sehingga sangat sulit untuk mendapatkan tanaman nilam di Kabupaten Jember.

Berikut adalah tabel penerimaan dari penjualan minyak atsiri berbahan baku nilam oleh UD.Barokah Atsiri.

Tabel 1 Penerimaan Penjualan Minyak Atsiri Berbahan Nilam

\begin{tabular}{ccccc}
\hline Th & Produksi & $\begin{array}{c}\text { Harga/Liter } \\
(\mathrm{Rp})\end{array}$ & Proses & $\begin{array}{c}\text { Penerimaan } \\
(\mathrm{Rp})\end{array}$ \\
\hline 1 & 220,5 & 1.000 .000 & 49 & $\begin{array}{c}220.500 .00 \\
0\end{array}$ \\
2 & 337,5 & 425.000 & 75 & $\begin{array}{c}143.437 .50 \\
0\end{array}$ \\
3 & 90 & 425.000 & 25 & $\begin{array}{c}38.250 .000 \\
4\end{array}$ \\
& 432 & 450.000 & 72 & $\begin{array}{c}194.400 .00 \\
0\end{array}$ \\
5 & 288,6 & 550.000 & 74 & $\begin{array}{c}158.730 .00 \\
0\end{array}$ \\
6 & 99 & 565.000 & 30 & 55.935 .000
\end{tabular}

\begin{tabular}{ccccc}
7 & 72 & 600.000 & 20 & 43.200 .000 \\
8 & 33 & 600.000 & 10 & 19.800 .000 \\
\hline \multicolumn{5}{l}{ Sumber: Data primer diolah $(2016)$}
\end{tabular}

(b) Arus Biaya

Komponen biaya yang dikeluarkan dalam usaha penyulingan minyak atsiri berbahan baku nilam mencakup biaya investasi dan biaya reinvestasi serta biaya operasional yaitu biaya variabel dan biaya tetap. Pengeluaran biaya investasi dan pengeluaran biaya operasional pada kondisi tanpa risiko berdasarkan data hasil pengumpulan.Berikut komponen arus biaya yang ada dalam usaha penyulingan minyak atsiri berbahan baku nilam di UD Barokah Atsiri:

(1) Biaya Investasi

Biaya invetasi yang ada pada penyulingan minyak atsiri berbahan nilam dikeluarkan pada saat usaha akan dijalankan. Biaya ini merupakan dana dalam pengadaan barang-barang investasi. Biaya investasi penyulingan minyak atsiri berbahan baku nilam UD.Barokah Atsiri dapat dilihat pada Tabel di bawah ini.

Tabel 2.Biaya Investasi UD Barokah Atsiri

\begin{tabular}{cccc}
\hline No & Jenis Investasi & \multicolumn{2}{c}{ Harga } \\
\hline 1 & Pembelian Tanah & Rp & 150.000 .000 \\
2 & Bangunan Sipil & Rp & 25.000 .000 \\
3 & Peralatan Penyulingan & Rp & 75.000 .000 \\
\hline & Total & Rp & 250.000 .000
\end{tabular}

Sumber: Data primer diolah (2016)

(2) Biaya Variabel

Biaya variabel merupakan salah satu komponen biaya operasional dalam kegiatan bisnis. Biaya variabel yang dikeluarkan oleh UD.Barokah Atsiri dalam melakukan proses penyulingan adalah biaya pembelian bahan baku yaitu berupa tanaman nilam dengan harga per $\mathrm{kg}$ rata-rata sebesar $\mathrm{Rp}$ 1.500. Biaya ini dapat berubah berdasarkan jumlah tanaman nilam yang diperoleh pada setiap proses penyulingan.

Biaya variabel yang dikeluarkan pada proses penyulingan dimulai pada tahun pertama umur proyek. Biaya ini keluar hanya pada saat UD.Barokah Atsiri melakukan kegiatan penyulingan. Sedangkan pada masa istirahat setelah periode berakhir biaya ini tidak dikeluarkan. Besaran nilai biaya variabel tergantung pada jumlah tanaman nilam yang didapatkan untuk proses penyulingan. Semakin banyak banyak tanaman nilam yang didapatkan maka biaya variabel yang dibutuhkan akan semakin besar dan sebaliknya.

(3) Biaya Tetap

Biaya tetap merupakan komponen terakhir dalam biaya operasional setelah biaya variabel. Tidak seperti biaya variabel besaran biaya tetap yang dikeluarkan UD.Barokah Atsiri tidak dipengaruhi jumlah tanaman nilam yang diperoleh untuk proses penyulingan yang dibesarkan per 
periodenya.

Ada beberapa komponen yang dikeluarkan UD.Barokah Atsiri dalam setiap satu kali proses. Komponen biayanya adalah biaya penyusutan, biaya pemeliharaan, biaya upah tenaga kerja dan biaya pembelian kayu bakar. Berikut tabel 5.3 komponen biaya tetap yang dikeluarkan UD.Barokah Atsiri pada setiap tahunnya.

\begin{tabular}{|c|c|c|}
\hline No & Komponen Biaya & Jumlah (Rp) \\
\hline 1 & Penyusutan & $6.700 .000 /$ tahun \\
\hline 2 & Pemeliharaan & 700.000/tahun \\
\hline 3 & Upah Tenaga Kerja & 200.000/Proses \\
\hline 4 & $\begin{array}{l}\text { Pembelian Kayu } \\
\text { Bakar }\end{array}$ & 250.000/Proses \\
\hline
\end{tabular}

Sumber : UD.Barokah Atsiri (Data diolah)

\section{Hasil Analisis Aspek Finansial}

Dalam penelitian ini digunakan empat kriteria investasi untuk mengukur kelayakan usaha penyulingan minyak atsiri berbahan baku nilam pada UD.Barokah Atsiri. Empat kriteria tersebut adalah Net Present Value (NPV), Internal Rate of Return (IRR), Net Benefit Cost Ratio (Net B/C) dan Payback Periode (PBP). Pada penilaian kriteria investasi jika nilai NPV lebih besar darinol, IRR lebih besar dari discount rate $(6$ persen), Net B/C lebih besar dari nol, serta PBP lebih cepat dari umur ekonomis peralatan penyulingan maka usaha yang dilakukan oleh UD.Barokah Atsiri dikatakan layak untuk dilakukan.

\begin{tabular}{|c|c|c|}
\hline No & Kriteria Investasi & Hasil Perhitungan \\
\hline 1 & NPV (Rp) & 224.535 .234 \\
\hline 2 & Net $B / C$ & 1,89 \\
\hline 3 & IRR (\%) & 36 \\
\hline 4 & PBP & 1 tahun 6 bulan \\
\hline
\end{tabular}

224.535.234, hasil tersebut menunjukkan bahwa manfaat bersih yang diperoleh UD.Barokah Atsiri dari penyulingan tanaman nilam menjadi minyak atsiri selama 8 tahun dengan tingkat diskonto 6,00 persen sebesar Rp 224.535.234. Nilai tersebut juga telah memenuhi persyaratan kelayakan untuk nilai NPV karena nilai yang dihasilkan telah lebih dari nol rupiah.

Kriteria selanjutnya adalah Net B/C, berdasarkan perhitungan pembagian net benefit positip dibagi dengan net benefit negatip (nilai absolut) hasilnya adalah 1,89. Artinya, satu satuan biaya yang dikeluarkan akan menghasilkan manfaat sebesar 1,89 satuan. Nilai ini juga dikatakan layak karena lebih dari satu satuan.

Nilai kriteria kelayakan kedua adalah IRR dengan nilai 36 persen. Hal tersebut memperlihatkan bahwa tingkat pengembalian yang dihasilkan dari usaha penyulingan tanaman nilam menjadi minyak atsiri sebesar 25,14 persen dalam satu tahun (delapan periode). Nilai IRR juga telah memenuhi syarat kelayakan suatu proyek karena nilainya lebih besar dari nilai tingkat diskonto yang dipakai dalam perhitungan (6 persen).

Investasi lahan dan peralatan penyulingan akan kembali dalam jangka waktu 1 tahun, 6 bulan. Nilai tersebut menunjukkan bahwa seluruh biaya investasi yang dikeluarkan pada tahap persiapan proyek akan dapat dikembalikan pada tahun kedua. Nilai itu juga layak karena jangka waktu pengembalian lebih kecil dari umur ekonomis investasi terlama yaitu untuk peralatan penyulingan selama 15 tahun. Oleh karena itu, dapat disimpulkan bahwa usaha penyulingan tanaman nilam menjadi minyak atsiri oleh UD.Barokah Atsiri layak untuk dikerjakan karena keempat kriteria kelayakan yang dihitung telah lebih dari prasayarat kelayakan proyek.

\section{Hasil Analisis Aspek Teknologi}

Aspek teknologi merupakan suatu aspek yang berhubungan dengan teknologi peralatan yang digunakan dalam suatu usaha. Peralatan dengan teknologi yang bagus dapat mempermudah serta memperlancar proses suatu usaha. Dalam penelitian ini UD. Barokah Atsiri menggunakan peralatan untuk mempermudah melakukan proses penyulingan dari tanaman nilam menjadi minyak atsiri berbahan nilam. Peralatan yang digunakan dalam penyulingan tergantung pada cara penyulingannya.

Pada UD. Barokah Atsiri menerapkan sistem penyulingan dengan air dan uap atau sistem kukus. Prinsip kerja dari penyulingan dengan sistem ini, ketel penyulingan diisi air sampai pada batas saringan. Bahan baku yang dalam hal ini adalah nilam diletakkan diatas saringan, sehingga tidak berhubungan langsung dengan air tetapi berhubungan langsung dengan uap air.

Ketel untuk penyulingan pada UD. Barokah Atsiri sudah terbuat dari bahan stainless steel/baja tak berkarat sehingga dapat menghasilkan minyak dengan kualitas terbaikSebab ada beberapa jenis logam tertentu yang dapat bereaksi atau bersenyawa dengan minyak nilam sehingga dapat menurunkan kualitas minyak nilam. UD. Barokah Atsiri memiliki peralatan penyulingan yang memadai terbukti sudah menjual minyak nilam mulai tahun 2008 hungga saat ini di beberapa tempat di Jawa Timur seperti Malang dan Surabaya. 
Jemi Cahya Adiwijaya, Uyun Erma Malika, Kelayakan Usaha Penyulingan Minyak Atsiri Berdasarkan Aspek Finansial dan Teknologi

\section{KESIMPULAN DAN SARAN}

Kesimpulan

Berdasarkan hasil penelitian dan analisis yang telah dilakukan pada usaha penyulingan tanaman nilam oleh UD. Barokah Atsiri, dapat diperoleh kesimpulan sebagai berikut :

1. Usaha penyulingan tanaman nilam yang dilakukan oleh UD. Barokah Atsiri dinilai layak dari aspek finansial. Perhitungan kelayakan usaha yang dilakukan sudah melampui standart batas yang disyaratkan. Sehingga usaha penyulingan tanaman nilam oleh UD. Barokah Atsiri dapat dilanjutkan.

2. Teknologi peralatan yang digunakan oleh UD.Barokah Atsiri dalam operasional proses penyulingan juga dapat dinilai layak. Peralatan yang digunakan sudah berbahan modern sehingga tidak mempengaruhi kualitas minyak yang dihasilkan.

Saran

Perlu adanya suatu penelitian yang mendalam terkait budidaya maupun usaha penyulingan tanaman nilam di Kabupaten Jember. Terutama untuk kelayakan usaha penyulingan nilam baik dari aspek finansial maupun non finansial seperti aspek manajemen, aspek hukum atau legalitas, aspek teknis, dll.

\section{UCAPAN TERIMA KASIH}

Ucapan terima kasih ditujukan kepada Pusat Penelitian dan Pengabdian kepada Masyarakat (P3M) Politeknik Negeri Jember yang telah mendanai kegiatan penelitian ini.

\section{DAFTAR PUSTAKA}

Gray, C., P. Simanjuntak, L.K Sabur, P.F.L Maspaitella, and R.C.G Varley. 2007. Pengantar Evaluasi Proyek. Edisi Kedua. Jakarta : PT Gramedia Pustaka Utama.

Guenther, Ernest. 1987. Minyak Atsiri Jilid 1. Jakarta: UI Press

Martono dan D.A Harjito. 2008. Manajemen Keuangan. Yogyakarta: Ekonisia Kampus Fakultas UII Yogyakarta

Santoso, Budi H. 1990. Nilam Bahan Industri Wewangian. Yogyakarta: Kanisius

Sugiyono, 2011. Metode Penelitian Kuantitatif Kualitatif dan R\&D. Bandung: Alfabeta.
Sundjaja, R.S, dan I. Barlian, 2002. Manajemen Keuangan. Jakarta : PT Prenhallindo.

Soeharto, I. 2002. Studi Kelayakan Proyek Industri. Jakarta: Erlangga.

Umar, H. 2003. Studi Kelayakan Bisnis. Edisi Kedua. Jakarta : PT Gramedia Pustaka Utama. 